\title{
ERRATUM
}

\section{Magnetic resonance imaging studies of age-dependent responses to scaled focal brain injury in the piglet}

TO THE READERSHIP: An error appeared in the article by Duhaime et al. (Duhaime AC, Hunter JV, Grate LL, et al. Magnetic resonance imaging studies of age-dependent responses to scaled focal brain injury in the piglet. J Neurosurg. 2003;99[3]:542-548).

In the Surgical Procedure and Model section of the Materials and Methods and in the legend of Fig. 1, the time at which the spring-loaded indentor tip was fired was given as $400 \mathrm{msec}$. The correct timeframe is $4 \mathrm{msec}$. The corrected sentence and figure legend are shown below.

The spring-loaded indentor tip was fired at a time course of $4 \mathrm{msec}$ and then removed.

FIG. 1. Photograph of the scaled cortical impact device. After craniectomy, the dura mater is opened widely, the device is firmly attached to the skull, and indentation occurs directly to the exposed cortical surface. The diameter and depth of indentation are scaled to be proportional to brain growth, displacing approximately $1 \%$ of the total brain volume over 4 msec.
The article has been corrected online as of May 29, 2020 .

Ann-Christine Duhaime, MD

Massachusetts General Hospital, Boston, MA

INCLUDE WHEN CITING

Published online May 29, 2020; DOI: 10.3171/2020.5.JNS2030542a.

CAANS 2020, except where prohibited by US copyright law 